\title{
Representação Social de saúde-doença nos textos jornalísticos veiculados na revista Veja
}

\author{
Representation Social health-disease in journalistic texts conveyed in \\ magazine Veja
Representación Social de salud-enfermedad en textos periodísticos transportan en revista Veja

\author{
Representation Sociale santé-maladie textes journalistiques transportés dans \\ magazine Veja \\ Jacir Alfonso Zanatta ${ }^{1}$ \\ Bianka Macário ${ }^{1}$ \\ Silvia Santana Zanatta ${ }^{1}$
}

Recebido em 14/03/2017; revisado e aprovado em 17/05/2017; aceito em 23/05/2017

DOI: http://dx.doi.org/10.20435/inter.v17i4.1525

\begin{abstract}
Resumo: A relação saúde e doença não é neutra. Essa relação está permeada pelos interesses de diferentes frações de classes envolvidas, demonstrando que, em sua essência, ela sempre foi um fenômeno político. A revista selecionada para entender como a saúde-doença vem sendo tratada pela mídia impressa foi a revista Veja, veículo impresso semanal de maior circulação no Brasil.
\end{abstract}

Palavras-chave: saúde-doença; jornalismo; representação social.

Abstract: The relationship between health and sickness is not neutral. This relationship is permeated by the interests of different fractions of the classes involved, demonstrating that, in its essence, it was always a political phenomenon. The magazine selected to understand how health and sickness is being addressed by the print media was Veja magazine, a weekly printed publication with the largest circulation in Brazil.

Key words: health-disease; journalism; social representation.

Resumen: La relación entre la salud y la enfermedad no es neutral. Esta relación está permeado por los intereses de las diferentes fracciones de las clases involucradas, lo que demuestra que, en su esencia, que siempre fue un fenómeno político. La revista seleccionada para entender cómo la salud-enfermedad ha sido tratada por los medios de impresión fue la revista Veja, vehículo impresa semanal de mayor circulación en Brasil.

Palabras clave: salud-enfermedad; periodismo; la representación social.

Résumé: La relation entre la santé et la maladie ne sont pas neutres. Cette relation est imprégnée par les intérêts des différentes fractions de classes impliquées, ce qui démontre que, dans son essence, il a toujours été un phénomène politique. Le magasin sélectionné pour comprendre comment la santé- maladie a été traitée par la presse écrite a été le magazine Veja, véhicule imprimée hebdomadaire avec le plus grand tirage au Brésil

Mots-clés: la santé-la maladie; journalisme; la représentation sociale.

\section{INTRODUÇÃO}

O presente artigo, desenvolvido com base na Teoria das Representações Sociais, tem como objetivo principal analisar como a questão da saúde-doença é tratada na mídia impressa nacional. A coleta de dados foi feita com base na análise de conteúdo, e a revista selecionada para entender como a saúde-doença vem sendo tratada pela mídia impressa foi a revista Veja, veículo impresso semanal de maior circulação no Brasil. Para a presente pesquisa, foram analisadas as

\footnotetext{
1 Universidade Católica Dom Bosco, Campo Grande, Mato Grosso do Sul, Brasil.
} 
revistas da terceira semana dos meses de julho a dezembro de 2015, totalizando seis revistas. Os dados obtidos mostram que os profissionais de jornalismo que escrevem para a revista Veja, trabalham dentro da perspectiva biomédica de saúde, abordando sempre as questões de causa e efeito. Com isso, foi possível constatar que a mídia impressa nacional não valoriza a prevenção nem a atenção primária em saúde, focando sempre nas questões epidemiológicas que dão maior impacto na população, esquecendo de trabalhar nas suas matérias as questões relacionadas com a prevenção.

Com relação aos resultados, é possível notar que a questão saúde-doença é pouco abordada na revista, comparando com a quantidade de textos publicados. Chama a atenção dos pesquisadores o fato de que, nas edições analisadas, nenhuma delas teve mais do que dois textos publicados sobre a relação saúde-doença, e as revistas de julho e dezembro não apresentam nenhum texto ligado à temática pesquisada. Dos 119 textos analisados nas seis edições, apenas seis apresentavam uma relação com a temática de saúde-doença. Todos dentro de uma vertente ideológica ligada ao modelo biomédico. Mas é importante destacar que, nos textos analisados, fica evidente que os profissionais de jornalismo descrevem os fatos sem, no entanto, se mostrarem preocupados em apresentar um novo viés diferente do proposto pelo modelo biomédico em questão. Também chama a atenção o fato de que, nos textos, os profissionais da comunicação utilizam sempre as fontes oficiais para respaldar a relação saúde-doença, o que indiretamente reforça a reprodução de um modelo que desvaloriza a prevenção e acaba por reproduzir um modelo alicerçado na autoridade médica, desvalorizando assim, uma prática ampliada de saúde.

\section{TEORIA DAS REPRESENTAÇÕES SOCIAIS}

Escolher a revista de maior circulação nacional como base de análise para se perceber como a saúde-doença vem sendo trabalhada pela mídia significa levar em consideração as representações sociais construídas pela mídia. Percebe-se assim, que quanto menos as pessoas pensam nas representações, quanto menos tomam consciência delas, maior se torna sua influência. Para Jovchelovitch (2008, p. 35) as representações "implicam um trabalho simbólico que emerge das inter-relações Eu, Outro e Objeto-Mundo e, como tal, têm o poder de significar, de construir sentido, de criar realidade". Nota-se assim, que o status da representação é polivalente. As representações são construções ontológicas, epistemológicas, psicológicas, sociais, culturais e históricas. Sendo assim, elas constroem o real, mas nunca capturam plenamente a totalidade da realidade, mesmo que desejem fazê-lo. E, no nosso entender, a revista Veja contribui com a construção de determinada representação social de saúde-doença na população brasileira.

Para Moscovici (2011) os indivíduos não são apenas processadores de informações, nem meros portadores de ideologias ou crenças coletivas, mas pensadores ativos, que produzem e comunicam representações e soluções específicas para as questões que se colocam a si mesmos. Percebe-se, assim, que todo o saber depende de um contexto e está enraizado em um modo de vida e, muitas vezes, a mídia contribui para reproduzir esse contexto e esse modo de vida. Buscando fazer uma análise do tecido social, Rêses (2003) mostra que a teoria das Representações Sociais se dirige à formação das explicações produzidas pelo senso comum em sociedades complexas e não exatamente às formas de saber mais elaboradas ou estruturadas.

Para Rêses (2003, p. 194) "as representações constituem modos de vida e formas de comunicação entre as pessoas; por isso, elas são Representações Sociais”. As Representações Sociais, portanto, orientam e organizam as condutas e as comunicações sociais, assim como intervêm na

INTERAÇÕES, Campo Grande, MS, v. 18, n. 4, p. 207-219, out./dez. 2017. 
difusão e na assimilação de conhecimentos, no desenvolvimento individual e coletivo, na definição das identidades pessoais e sociais, na expressão dos grupos e nas transformações sociais.

Herzlich (1991), no entanto, alerta para o fato de que as Representações Sociais não são o somatório das representações individuais, elas se constituem numa realidade que se impõe ao indivíduo. Segundo Herzlich (1991), é importante observar que a Representação Social não é mero reflexo do real, mas sua construção. Percebe-se assim, que se faz necessário ter um cuidado redobrado para não se incorrer no erro de defender que, a partir de agora, tudo é Representação Social. Lembre-se que as Representações Sociais se dão nas relações, entendidas como um fenômeno comunicativo e dialógico. Por essa razão, entendemos que a revista Veja contribui para que um determinado tipo de representações sociais de saúde-doença se espalhem entre a população.

Guareschi e Jovchelovitch (2011) explicam que as Representações Sociais enquanto teoria são altamente questionadoras e não se acomodam com o já pensado. Por isso ela busca constantemente o novo onde o peso hegemônico do pensamento tradicional impõe suas contradições. Esta é a capacidade e a elasticidade que a teoria apresenta. Isso permite que ela se renove constantemente e tenha condições de se adaptar a situações adversas. De acordo com Alaya (2011), a teoria das Representações Sociais baseia-se em um esquema radicalmente diferente daquele admitido nas teorias clássicas do conhecimento.

a representação não é um simples reflexo ou uma reprodução da realidade, mas, uma reconstrução por distorções, exclusões e adições. As representações não fazem apenas representar o real, eles lhe dão forma, até certo ponto. A informação recebida é transformada. Portanto, há um vaivém de informações, uma interação entre a representação e a realidade. (ALAYA, 2011, p. 270).

Complementando a concepção defendida acima, Guareschi (2011, p. 162) alerta para o fato de que "o conceito de Representação Social é dinâmico e explicativo, tanto da realidade social, como física e cultural. Possui uma dimensão histórica e transformadora. Junta aspectos culturais, cognitivos e valorativos, isto é, ideológicos". Pelo exposto, é possível perceber que as Representações Sociais estão em constante construção. São realidades dinâmicas e não estáticas. Essa dinamicidade permite que elas sejam reelaboradas e modificadas constantemente. São essas características que permitem a elasticidade à teoria e fazem com que sejam ampliadas e enriquecidas com novos elementos todos os dias, elementos esses que podem vir reproduzidos nas concepções jornalísticas veiculadas na mídia impressa nacional.

Percebe-se assim que as Representações Sociais são capazes de estabelecer conexões entre as abstrações do saber e das crenças com a concretude da vida do indivíduo em seus processos de troca com os outros. Nota-se, então, que, enquanto teoria, as Representações Sociais oferecem um ótimo suporte às investigações desde que consiga partir do conhecimento do sujeito ou grupo estudado, mostrando como esse conhecimento orienta as suas práticas cotidianas. Dessa forma, o conhecimento no contexto das representações se transforma diariamente. Assim, ao estudar as Representações Sociais, é preciso levar em consideração a visão que os indivíduos ou grupos possuem e empregam na forma de agir e se posicionar perante o mundo e, na contemporaneidade, nada melhor do que a mídia para construir essa visão de mundo.

Nota-se, dessa forma, que, dentro dessa abordagem, os sistemas centrais e periféricos das representações podem parecer contraditórios, mas são, na verdade, complementares. Fica claro, então, que os elementos periféricos são sensíveis ao contexto imediato e têm um caráter 
evolutivo que permite a adaptação à realidade concreta e à diferença de conteúdo. Por serem mais concretos, os elementos periféricos, respondem por três funções: concretização, regulação e defesa. Chaves e Silva (2011) argumentam ainda que as Representações Sociais permitem justificar comportamentos e tomadas de posição. Com isso, elas contribuem para preservar e justificar a diferenciação social, podendo, então, estereotipar as relações entre grupos, contribuir para a discriminação ou para a manutenção da distância social entre eles. São estas questões que nos interessam, pois pretendemos perceber qual o conceito de saúde-doença que está sendo veiculado pela mídia impressa nacional.

Mas é preciso ficar atento ao alerta feito por Jodelet (2009), ao afirmar que as Representações Sociais são fenômenos complexos sempre ativados e em ação na vida social. Por isso, elas envolvem elementos informativos, cognitivos, ideológicos, normativos, crenças, valores, atitudes, opiniões e imagens, formando uma totalidade significante em relação à ação. Assim, por serem elaboradas na fronteira entre o psicológico e o social, as Representações Sociais são capazes de estabelecer conexões entre as abstrações do saber e das crenças, e a concretude da vida do indivíduo em seus processos de troca com os outros. Dessa forma, fica claro que, para descrever as Representações Sociais em sua pluralidade, é preciso conhecer quem fala, qual a sua posição na estrutura social e quais os espaços sociais que produzem esse discurso.

\section{OS MODELOS DE SAÚDE NA MÍDIA IMPRESSA NACIONAL}

Para iniciar esta pequena reflexão sobre a relação de saúde-doença, é importante lembrar do alerta feito por Iyda (1994), ao defender que a relação saúde e doença não é neutra, assim como toda a produção jornalística veiculada nas páginas da revista Veja. Essa relação está permeada pelos interesses de diferentes frações de classes envolvidas, demonstrando que, em sua essência, ela sempre foi um fenômeno político. De acordo com lyda (1994), a Saúde Pública faz parte da institucionalização e consolidação de um Estado burguês, que se forma a partir da crise e desintegração de um regime colonial português. Iyda (1994) defende que a questão da saúde no Brasil sempre foi tratada de forma fragmentada, o que contribui para a alienação, para a divisão dos agentes sociais envolvidos e para reforçar a dicotomia saúde-doença.

Coelho e Almeida Filho (2002) defendem que a dificuldade de conceituar o significado de saúde é resultado da influência da indústria farmacêutica e de uma cultura da doença, que têm restringido o interesse e os investimentos de pesquisa a um tratamento teórico e empírico da questão da saúde como mera ausência de doença. Esta mesma indústria farmacêutica tem poder de ocupar os espaços da mídia e, sem que os profissionais percebam, produzir notícias que, no seu contexto, vendem um modelo biomédico de saúde, deixando de lado o modelo biopsicossocial ou mesmo uma prática ampliada de saúde para a população brasileira. Mesmo sabendo dessas questões, é necessário optar por um conceito de saúde que permita discutir a realidade e os dados coletados no decorrer desta pesquisa.

Dessa forma, Minayo (1999) esclarece que a saúde enquanto questão humana e existencial deve ser compartilhada indistintamente por todos os segmentos da sociedade. No entanto é interessante observar que as condições de vida e de trabalho qualificam de forma diferenciada a maneira pela qual as classes pensam, sentem e agem a respeito dela. Minayo (1999, p. 15) argumenta que "para todos os grupos, ainda que de forma específica e peculiar, a saúde e a doença envolvem uma complexa interação entre os aspectos físicos, psicológicos, sociais e 
ambientais" da existência humana, que atribui significado a cada ato desenvolvido no percurso de sua existência.

Mas é importante observar que, no decorrer da história, a saúde não representou a mesma coisa para todas as pessoas. Dessa forma, Scliar (2007) argumenta que o conceito de saúde reflete sempre a conjuntura social, econômica, política e cultural de uma época e de uma determinada sociedade. Minayo (1988) por sua vez, alerta para o fato de que, em qualquer doença, é o ser humano integral que está em jogo. Por isso é importante prestar atenção às condições materiais da existência no tempo e no espaço.

Dentro dessa mesma linha de reflexão, Sarriera et al. (2003) explica que é preciso levar em consideração o fato de que o conceito de saúde apresentado pelos diferentes paradigmas está relacionados a elementos como a concepção de homem, mundo, realidade, influência do contexto social e possibilidade de mudança. Mas a definição dada por Segre e Ferraz (1997, p. 542), quando afirmam que "saúde é um estado de razoável harmonia entre o sujeito e sua própria realidade", chega bem perto do entendimento que se tem de saúde durante a realização desta pesquisa. É importante observar que, para Segre e Ferraz (1997), o homem sintonizado com o ambiente em que vive tende a divergir de posturas impostas pela sociedade. É preciso prestar atenção para conseguir entender que algumas considerações sobre o conceito de saúde-doença visam apenas atenuar a tendência positivista dos conceitos de saúde que aí estão. De acordo Serge e Ferraz (1997), despertar uma visão anti-positivista e mais humana das atividades dos profissionais de saúde, pode contribuir para um contato mais empático e, consequentemente, mais ético, entre os profissionais da saúde e população assistida.

É importante ressaltar que os autores citados acima também encontram eco no pensamento de Dejours (1986, p. 08) quando este argumenta que "o estado de saúde não é certamente um estado de calma, de ausência de movimento, de conforto, de bem-estar e de ociosidade. É algo que muda constantemente e é muito importante que se compreenda esse ponto". Isso mostra que pensar a saúde é compreendê-la a partir do movimento do corpo, sem utilizar um modo ou uma postura rígida. Note-se que para Dejours (1986, p. 11) saúde é "antes de tudo uma sucessão de compromissos com a realidade; são compromissos que se assumem com a realidade, e que se mudam, se reconquistam, se redefinem, que se perdem e que se ganham". Ou seja, a saúde é um processo em permanente construção e conquista. Observa-se ainda, que o conceito descrito por Dejours (1986) leva em consideração três facetas: a) a realidade do ambiente material; b) a realidade afetiva, relacional e familiar; e c) a realidade social. Estas facetas levam em consideração o bem-estar físico, psíquico e social.

No entanto, Canguilhem (2005) defende que as doenças são apenas os instrumentos da vida por meio dos quais os seres vivos, quando se trata do homem, se vê obrigado a se reconhecer mortal. Para o autor, a saúde não é somente a vida no silencio dos órgãos, mas também a vida na discrição das relações sociais. Dessa maneira, a saúde serve como instrumento para que os governantes mantenham a ordem social. Pelo exposto, é possível perceber, no decorrer desta pesquisa, que a questão da saúde depende mais dos interesses e da ideologia dos grupos políticos e economicamente poderosos do que de sua validade médica ou científica.

Nesse sentido, é importante ressaltar que esta pesquisa busca levar em consideração um conceito ampliado de saúde. Dessa forma, é importante observar que, para Traverso-Yépez (2001), trabalhar dentro de um conceito ampliado de saúde é buscar compreender que o sofrimento e a doença não devem se reduzir a uma evidência orgânica, natural, objetiva, mas estão 
intimamente relacionados com as características de cada contexto sociocultural. Contini (2010) também defende um modelo ampliado de saúde ao argumentar que a saúde é um complexo processo qualitativo que define o funcionamento completo do organismo, integrando de forma sistêmica o somático e o psíquico. Com essa postura, a autora assume também, como consequência, que a Saúde é condicionada pela nutrição, moradia, higiene, condições de trabalho, lazer, educação e todos os demais fatores ambientais, questões esquecidas no decorrer dos textos jornalísticos sobre a saúde no Brasil.

Para concluir, é importante ressaltar que Backes et al (2009, p. 112) defendem que "saúde, em sua concepção ampliada, é o resultado das condições de alimentação, moradia, educação, meio ambiente, trabalho e renda, transporte, lazer, liberdade e, principalmente, acesso aos serviços de saúde". Percebe-se assim, que está na hora de compreender a saúde em suas diferentes dimensões, com o enfoque voltado para a promoção e proteção da saúde. Isso permite que se trabalhe dentro de práticas mais integradoras em saúde. Só assim, será possível deixar de lado as desigualdades sociais que impedem o acesso aos serviços de saúde e à informação por parte da população como um todo.

\section{COMO SE CONSTRÓI O TEXTO JORNALÍSTICO NA MÍDIA IMPRESSA}

No mundo atual, marcado pelo jornalismo de oligopólio, os textos veiculados pela mídia impressa e eletrônica tendem a se tornar cada vez mais minimalistas e fragmentados, marcando a aniquilação do jornalismo autoral. Numa luta ingrata contra o tempo, a pressão das redações, a ditadura do lead e as formas de expressão dominadas pelos clichês, o jornalista precisa exercitar com consciência a sua principal função, a de elaborar textos que tenham por matéria prima, além da fundamentação sólida das informações apuradas, o atributo da criatividade. Os textos analisados mostram que essas questões não estão mais sendo levadas em consideração pelos profissionais da mídia impressa.

De acordo com Lage (1987), a notícia é o relato de uma série de fatos a partir do mais importante ou interessante. Assim, é bom esclarecer que, no processo de produção da notícia, há três fases: a) seleção dos eventos; b) ordenação dos eventos; e c) nomeação. Mas o que não pode ficar de fora é o fato de que, na construção dos textos jornalísticos sobre saúde-doença, os profissionais não levam em conta as concepções que estão veiculando na hora de produzir uma matéria, como também não observam o jogo ideológico ou político nas questões relacionadas à saúde pública.

Os textos da revista Veja analisados nesta pesquisa mostram que os profissionais de comunicação se preocupam com o modelo jornalístico, buscando prender a atenção do leitor ao texto que estão escrevendo, mas não conseguem perceber as relações de poder que estão por trás daquilo que produzem. Por outro lado, não podemos esquecer que um texto jornalístico precisa conter alguns itens como: a) dar ao leitor os antecedentes completos dos fatos que originaram a notícia; b) mostrar o alcance que tiveram as circunstâncias, no momento em que os fatos ocorreram, e dizer o que poderá resultar no futuro, em consequência delas; e c) comentar todos esses fatos e situações anteriormente descritas, o que consistiria em uma análise. Mas essas recomendações não são percebidas nos textos veiculados na revista Veja no que se refere à saúde-doença.

O jornalismo é uma conversa por escrito, simples e atual entre um veículo de comunicação de massa e seus leitores e, nesse ponto, entendemos que estudar a influência do texto jornalístico 
sob a ótica da Teoria das Representações Sociais é mais que salutar. Por isso não adianta dar apenas técnicas, é preciso formar cabeças pensantes que saibam empregar as técnicas. De acordo com Medina (1986), a técnica da entrevista no jornalismo pode apenas preencher os requisitos imediatos da notícia, ou pode servir como importante meio de comunicação social. No primeiro caso, basta para o jornalista o aprendizado prático, em pouco tempo estará apto para se desempenhar como um entrevistador médio. Já no segundo caso, preparo técnico e humanístico exige estudo, pesquisa, exercício permanente. $E$, os textos que analisamos mostram que esse preparo humanístico está em falta na produção dos textos da revista Veja.

\section{METODOLOGIA DA PESQUISA}

Quando se faz pesquisa, a gente se constitui como pesquisador no ato de pesquisar. Com isso, o percurso metodológico deve contribuir para que se pense diferente da forma como se pensava anteriormente. Mas não é fácil deixar de lado velhas amarras. No entanto o método não deve engessar a pesquisa, mas possibilitar que o pesquisador dialogue com a própria pesquisa. Esta pesquisa mostra que é possível trabalhar com a Teoria das Representações Sociais mantendo um rigor metodológico sem, no entanto, deixar de produzir com leveza e sensibilidade. Pelo exposto, fica fácil perceber o motivo pelo qual Moscovici (2011) argumenta que é fundamentalmente contra a tendência de se fetichizar o método qualitativo. Maffesoli (2007) defende que não se pode pensar sem alicerces. Assim, é possível notar que cada método possui uma maneira particular de constituir seu objeto de estudo. Dentro dessa mesma perspectiva de trabalho, Almeida e Cunha (2003) mostram que a ciência tem a ambição de intensificar o papel de explicadora da realidade, definindo regras, através de seus modelos teóricos, que acabam, também, por especificar e prescrever as ações humanas.

Mas, não se pode esquecer o alerta feito por Jovchelovitch (2011) quando defende que os saberes do cotidiano têm papel fundamental na reprodução de indivíduos, sociedades e culturas e, preocupados com essas questões, buscamos analisar a relação de saúde-doença veiculadas nas páginas da revista Veja. Percebe-se assim, que os saberes de diferentes esferas reconstituem e redefinem tanto o senso comum como o saber científico.

Buscando aprofundar a reflexão metodológica, Duveen (2003) explica que o conhecimento emerge do mundo onde as pessoas se encontram e interagem do mundo onde os interesses humanos, necessidades e desejos encontram expressão, satisfação ou frustração. Quem sabe seja, por isso, que o conhecimento surge das paixões humanas e, como tal, nunca é desinteressado. Esta pode ser uma das hipóteses utilizadas para justificar a falta de textos que trabalhem a relação saúde-doença nas páginas da revista Veja. Nessa mesma linha de raciocínio, Fazenda (1999) defende que, ao se desenvolver uma pesquisa científica, se faz necessário o preenchimento de três requisitos: a) a existência de uma pergunta que se deseja responder; b) a elaboração de um conjunto de passos que permitam obter a informação necessária para respondê-la; e c) a indicação do grau de confiabilidade na resposta obtida. As definições de Turato (2003) e Fazenda (1999) indicam que o método científico permite que o pesquisador construa conceitualmente imagens verdadeiras e impessoais da realidade, que possam ser submetidas a teses que comprovem ou não sua veracidade.

Pelo exposto acima, é possível afirmar que pensar a metodologia empregada num trabalho é acima de tudo, compreender o processo de produção do próprio conhecimento na trajetória de uma pesquisa. Por isso se faz necessário observar que, de acordo com Santos (2006), é preciso 
voltar às coisas simples e recuperar a capacidade de formular perguntas. E, uma pesquisa qualitativa, acima de tudo, deve ser alicerçada nas questões desenvolvidas pelo pesquisador.

É importante observar que para Gibbs (2009, p. 29) "não é necessário transcrever toda e qualquer informação coletada no projeto para analisá-la". Dessa forma, é possível perceber que a pesquisa qualitativa envolve interpretação. No entanto é bom lembrar que, na medida do possível, o pesquisador precisa interpretar as informações trazidas do campo e não impor uma interpretação com base em teorias preexistentes. Gibbs (2009) alerta ainda para o fato de que se o pesquisador não tomar algum cuidado, ele pode deixar passar na sua análise, os seus preconceitos.

Dessa forma, o pesquisador passa a ser uma parte importante na pesquisa qualitativa. Flick (2009, p. 124) argumenta que "a pesquisa qualitativa pode revelar possíveis conexões, razões, efeitos e mesmo a dinâmica dos processos sociais, e é apenas a pesquisa qualitativa com uma coleta não estruturada de dados que pode revelar isso". Percebe-se assim, que a qualidade na pesquisa qualitativa é o resultado de decisões tomadas pelo pesquisador. Com isso, Flick (2009) busca mostrar que a qualidade está diretamente ligada a questões éticas e com a transparência produzida na pesquisa.

Percebe-se, assim, que toda pesquisa qualitativa precisa trazer, no seu bojo, uma preocupação ética. Mas não é apenas isso, a realidade mostra que ética e pesquisa, bem como os resultados a que o pesquisador irá chegar, fazem parte de uma preocupação maior que envolve o ser humano e seus discursos. É importante observar ainda o alerta feito por lanni (2004) ao defender que a história do mundo moderno está registrada principalmente em narrativas. Elas são constantemente desafiadas a captar o visível e o invisível, a realidade e a interpretação que os pesquisadores fazem dela.

Percebe-se, assim, que como instrumento dialógico, a comunicação permite e faz com que as pessoas se aproximem dos demais seres que vivem e partilham este mundo neste momento. Medina (1986, p. 14) comenta que numa classificação sintética, a entrevista é classificada em dois grupos: "entrevistas cujo objetivo é espetacularizar o ser humano e entrevistas que esboçam a intenção de compreendê-lo". De acordo com a autora, na produção de um texto, sempre vai existir a participação invisível do autor que pode selecionar os traços considerados por ele fundamentais, dramatizando-os e levando em consideração a dinâmica interna da própria narrativa. Medina (2003) consegue mostrar como é possível utilizar a entrevista para captar o cotidiano, registrá-lo e trabalhar as várias facetas de cada discurso trazido à cena pelo entrevistador.

Observe que, ao narrar o mundo, cada ser humano busca organizá-lo conforme suas concepções e vivências. E, nessa retomada de percepções, Medina (2003, p. 49) vai além do trivial quando mostra que "a razão treinada para resultados imediatos perde a força do afeto e não dá margem a um insight criativo". Nesse contexto, é importante ressaltar que produzir um texto buscando enfocar a entrevista e o processo comunicativo como um princípio epistemológico é perceber que grande parte dos problemas sociais e humanos se expressa, de modo geral, na comunicação das pessoas. Por isso a comunicação permite conhecer as configurações e os processos subjetivos que caracterizam o ser humano e o modo como as diversas condições sociais afetam o homem.

Sendo assim, o presente artigo está alicerçado na análise de conteúdo dentro de uma perspectiva qualitativa e levando-se em consideração a Teoria das Representações Sociais. Levando-se em consideração a impossibilidade de se analisar toda a mídia impressa, optou-se 
pela revista de maior circulação nacional, a revista Veja. Para a presente pesquisa, foram analisadas as revistas da terceira semana dos meses de julho a dezembro de 2015, totalizando seis revistas. As seis revistas totalizaram 664 páginas e um total de 119 textos jornalísticos. Dos 119 textos jornalísticos, apenas seis apresentavam relação com a temática saúde ou doença.

\section{DISCUSSÃO DOS RESULTADOS}

Os dados obtidos mostram que os profissionais de jornalismo que escrevem para a revista Veja, trabalham dentro da perspectiva biomédica de saúde, abordando sempre as questões de causa e efeito. Com isso, foi possível constatar que a mídia impressa nacional não valoriza a prevenção nem a atenção primária em saúde, focando sempre nas questões epidemiológicas que dão maior impacto na população, esquecendo-se de trabalhar nas suas matérias as questões relacionadas com a prevenção.

De acordo com Sêga (2000), o social interfere de várias maneiras, pelo contexto que se situam os grupos, pela comunicação que se estabelece, pela bagagem cultural, pelos símbolos e códigos, valores e ideologias. Com relação aos resultados, é possível notar que a questão saúde-doença é pouco abordada na revista, comparando com a quantidade de textos publicados. Chama a atenção dos pesquisadores o fato de que, nas edições analisadas, nenhuma delas teve mais do que dois textos publicados sobre a relação saúde-doença.

Dos 119 textos analisados nas seis edições, apenas seis apresentavam uma relação com a temática. Todos dentro de uma vertente ideológica ligada ao modelo biomédico. Mas é importante destacar que, nos textos analisados, fica evidente que os profissionais de jornalismo descrevem os fatos, sem, no entanto, se mostrarem preocupados em apresentar um novo viés, diferente do proposto pelo modelo biomédico em questão. Também chama a atenção o fato de que, nos textos, os profissionais da comunicação utilizam sempre as fontes oficiais para respaldar a relação saúde-doença, o que indiretamente reforça a reprodução de um modelo que desvaloriza a prevenção e acaba por reproduzir um modelo alicerçado na autoridade médica, desvalorizando assim, uma prática ampliada de saúde.

A primeira edição analisada foi a de número 2435, de julho de 2015. A revista em questão saiu com 98 páginas e com 19 textos jornalísticos entre notícias e reportagens. Nenhum dos textos publicados nessa edição trouxe qualquer referência à temática da nossa pesquisa. Isso nos leva a perceber que, mesmo estando num mês em que a circulação de vírus é maior, não existiu por parte dos editores e repórteres da revista uma preocupação em publicar matérias alertando sobre os cuidados com as doenças respiratórias, comuns nessa época do ano. Nessa primeira edição analisada fica evidente que, na linha editorial da revista, as questões ligadas à saúde-doença só são lembradas como matérias quando alguma questão mais grave ligada à doença assombra a população como, por exemplo, o aumento dos casos de H1N1. Nessa edição especificamente nada foi produzido sobre saúde-doença. No nosso entender, a falta de matéria sobre o assunto está diretamente ligada a não existir naquele momento nenhuma doença alarmando a população. Dessa forma, a atenção básica à saúde e a prevenção acabam não tendo espaço na revista de maior circulação no Brasil.

No mês seguinte, encontramos nas 98 páginas da Veja, apenas uma reportagem sobre saúde-doença. A edição número 2439 de agosto de 2015, trouxe 18 matérias entre notícias e reportagens. 0 único texto sobre a temática pesquisada foi publicado na página 78 e estava 
veiculada com o título "A conta certa para emagrecer". A reportagem em questão estava diretamente ligada à vida fitness, valorizando o emagrecimento saudável e o cuidado com o corpo por meio da alimentação e exercícios físicos. É interessante observar que a matéria valoriza os exercícios físicos para o corpo e traz como gancho a invenção de um aplicativo de celular criado para controlar a perda de peso. Mais do que se preocupar com as questões emergentes da saúde-doença da população, o texto valoriza a estética do corpo e não aborda em nenhum momento as questões políticas e ideológicas que estão por trás da tecnologia criada como mais um auxílio do culto ao corpo tão em voga no mundo contemporâneo.

Mas o que chama a atenção destes pesquisadores é a revista de setembro. A edição número 2444, foi veiculada com 114 páginas e 26 textos jornalísticos. Nessa edição, dois textos estavam diretamente ligados à questão da saúde-doença. O primeiro deles foi publicado na página 87, e fica evidente a força do modelo biomédico e da indústria farmacêutica e das empresas privadas sobre a produção jornalística. Com o título "Problema público, solução privada", a reportagem faz de forma direta um ataque ao modelo de saúde pública do Brasil, não levando em consideração que o Sistema Único de Saúde (SUS) brasileiro está sendo referência, como modelo, para vários países na Europa. De forma simplista, o jornalista acaba colocando que, se a saúde da população brasileira fosse privatizada, as empresas privadas resolveriam os problemas que atualmente temos na saúde pública. Com isso, no lugar de buscar compreender os motivos pelos quais o sistema de saúde brasileiro não funciona, a revista Veja se posiciona em defesa de uma saúde pública/privada, comprometendo milhões de brasileiros que não possuem condições de pagar por um plano de saúde privado e que encontram no SUS a única alternativa para o tratamento de doenças graves.

No segundo texto sobre saúde-doença veiculado na revista Veja de setembro, o foco fica sobre as questões cardiovasculares. A reportagem foi publicada na página 98 e trouxe como título "O número mágico da pressão sanguínea". O texto se concentra apenas em dar explicações sobre a forma ideal para medir a pressão sanguínea, que é atualmente de 12 por 8 . As questões diretamente ligadas aos cuidados básicos com a alimentação e com a própria saúde, como forma de prevenção de doenças, simplesmente não foram elucidadas pelo jornalista encarregado de produzir a reportagem. Percebe-se, assim, que o destaque dado pela revista às questões ligadas à saúde-doença estão sempre relacionadas a um processo medicamentoso de causa e efeito, sem levar em consideração as condições de vida da população brasileira, seu nível de instrução, poder aquisitivo e possibilidades de ter uma alimentação mais saudável.

Percebe-se, ainda, que as questões ligadas à saúde-doença também servem como modelo ao próprio sistema econômico. Isso fica evidente na edição número 2448, de outubro de 2015. A revista foi veiculada com 110 páginas e 19 textos jornalísticos. Na página 74, num texto ligado à economia brasileira, a palavra saúde aparece dando a entender que o sistema econômico nacional não está com sua saúde perfeita. Nota-se que os profissionais da comunicação utilizam de forma indevida a palavra saúde para buscar fazer um paralelo entre a saúde e a economia, o que, no nosso entender, acabou ficando sem sentido, mas nas entrelinhas se percebe uma valorização de um modelo de saúde alicerçado em causa e efeito buscando valorizar as formas de saúde privadas como modelo para toda a nação.

Com relação à edição número 2452 de novembro de 2015, pode-se afirmar que esta foi veiculada com 98 páginas e com 18 textos jornalísticos, sendo que, em apenas um deles, há relação saúde-doença, mesmo que estando diretamente ligada a estética do corpo. O texto 
está relacionado à beleza e foi publicado na página 82, com o título "Jovens no bisturi". O foco da matéria são as adolescentes que estão passando por cirurgias estéticas cada vez mais cedo. Em nenhum momento, se observou uma preocupação com a prevenção da saúde, mas com um modelo de intervenção e correção estética preocupada mais com a beleza do que propriamente com a saúde. Toda a matéria utiliza como foco principal a correção do tamanho do nariz e o aumento da mama nas adolescentes de 13 a 18 anos. Nessa reportagem, é possível perceber que o modelo jornalístico da revista Veja se preocupa mais com a descrição dos fatos, sem levar em consideração as possibilidades de uma prática ampliada de saúde que poderia contribuir para melhorar todo o sistema de saúde nacional.

A última edição analisada foi a de número 2457 de dezembro de 2015, que foi publicada com 126 páginas e com 19 textos jornalísticos. O que se percebe nessa edição é que estamos vivendo o auge do verão e, mesmo assim, nenhum dos 19 textos veiculados na revista fazem referência às questões dos cuidados com a saúde e com a proteção nos dias de calor ou de sol forte. Nota-se que este é um período de férias e, mesmo assim, a linha editorial da revista não traz nos seus textos os cuidados básicos necessários que se deve ter nessa época do ano. Este também é um período em que se tem os maiores índices de dengue no Brasil e, em nenhum momento, a revista se preocupou em produzir uma matéria alertando para os cuidados básicos que todo cidadão deve ter para que se possa combater a doença. As matérias ligadas à doença estão sempre relacionadas a epidemias. Conclui-se assim, que enquanto algo não se torna problema de saúde pública nacional, não merece destaque nas páginas da Veja.

\section{CONSIDERAÇÕES FINAIS}

A presente pesquisa mostra que a revista de maior circulação nacional, no que se refere à relação saúde-doença, trabalha dentro de uma perspectiva biomédica. A análise mostra que os profissionais da mídia, de uma forma generalista, apenas descrevem os fatos, sem observarem as relações ideológicas e políticas que estão postas nas questões ligadas à saúde-doença.

Não existe por parte dos profissionais da mídia a sensibilidade de compreenderem a saúde em suas diferentes dimensões, com o enfoque voltado para a promoção e proteção da saúde, permitindo assim que ao leitor sejam apresentadas as práticas mais integradoras em saúde.

A mídia impressa nacional, aqui representada pela revista Veja, não valoriza a prevenção nem a atenção primária em saúde, focando sempre nas questões epidemiológicas que dão maior impacto na população, esquecendo-se de trabalhar, nas suas matérias, as questões relacionadas com a prevenção. Exemplo disso é que, das 119 matérias analisadas, apenas seis textos faziam menção à saúde ou à doença da população. E chama também a atenção o fato de que os textos sobre saúde e doença mostravam muito mais uma relação com a estética do que propriamente com as questões ligadas à saúde dos brasileiros.

Hoje, num mundo onde o oligopólio midiático é um dos piores impedimentos ou limitação à liberdade dos cidadãos brasileiros de transformarem suas realidades, os textos veiculados pela mídia impressa e eletrônica tendem a se tornar cada vez mais minimalistas e fragmentados, marcando a aniquilação do jornalismo autoral. Numa luta ingrata contra o tempo, a pressão das redações, a ditadura dos modelos pré-estabelecidos, o jornalista precisa exercitar com consciência a sua principal função que é a de elaborar textos que tenham por matéria prima, fundamentação sólida das informações apuradas e, além de tudo, se enxergar como um agente social capaz de gerar mudança.

INTERAÇÕES, Campo Grande, MS, v. 18, n. 4, p. 207-219, out./dez. 2017. 


\section{REFERÊNCIAS}

ALAYA, D. B. Abordagens filosóficas e a teoria das representações sociais. In: ALMEIDA, A. M.; SANTOS, M. F. S.; TRINDADE, Z. A. (Org.). Teoria das Representações Sociais: 50 anos. Brasília: Technopolitik, 2011. p. 261-81.

ALMEIDA, A. M. O; CUNHA, G. G. Representações sociais do desenvolvimento humano. Psicologia: Reflexão e Crítica, v. 16, n. 1, p. 147-55, 2003.

BACKES, M. T. S; DA ROSA, L. M; FERNANDES, G. C. M; BECKER, S. G; MEIRELLES, B. H. S; SANTOS, S. M. Conceitos de saúde e doença ao longo da história sob o olhar epidemiológico e antropológico. Revista de Enfermagem, Rio de Janeiro, v. 17, n. 1, p. 111-7, jan./mar. 2009.

CANGUILHEM, G. Escritos sobre a medicina. Rio de Janeiro: Forense Universitária, 2005.

CHAVES, A. M.; SILVA, P. L. Representações Sociais. In. TORRES, A. R. R. et al. Psicologia Social: temas e teorias. Brasília: Technopolitik, 2011.

COELHO, M. T. A. D.; ALMEIDA FILHO, N. de. Conceitos de saúde em discursos contemporâneos de referência científica. História, Ciência, Saúde - Manguinhos, Rio de Janeiro, v. 9, n. 2, p. 315-33, maio/ ago. 2002.

CONTINI, M. de L. J. O psicólogo e a promoção de saúde na educação. São Paulo: Caso do Psicólogo, 2010.

DEJOURS, C. Por um novo conceito de saúde. Revista Brasileira de Saúde Ocupacional, v. 14, n. 54, p. 7-11, abr./jun. 1986.

DUVEEN, G. O Poder das ideias. In: MOSCOVICI, S. Representações sociais: investigação em Psicologia Social. Petrópolis: Vozes, 2003.

FAZENDA, I. (Org.). Metodologia da Pesquisa Educacional. São Paulo: Cortez, 1999.

FLICK, U. Qualidade na pesquisa qualitativa. Porto Alegre: Artmed, 2009.

GIBBS, G. Análise de dados qualitativos. Porto Alegre: Artmed, 2009.

GUARESCHI, P. Sem dinheiro não há salvação: ancorando o bem e o mal entre neopentecostais. In: GUARESCHI, S.; JOVCHELOVITCH, S. (Org.). Textos em Representações Sociais. 12. ed. Petrópolis: Vozes, 2011. p. 153-81).

GUARESCHI, P.; JOVCHELOVITCH, S. (Org.). Textos em representações sociais. 12. ed. Petrópolis: Vozes, 2011.

HERZLICH, C. A problemática da representação social e sua utilidade no campo da doença. Physis: Revista de Saúde Coletiva, Rio de Janeiro, v. 1, n. 2, p. 22-36, 1991. Disponível em: <http://www.scielosp.org/pdf/ physis/v1n2/02.pdf>. Acesso em: 9 maio de 2011.

IANNI, O. Variações sobre arte e ciência. Revista Tempo Social, São Paulo, v. 16, n. 1, 2004.

IYDA, M. Cem anos de saúde pública: a cidadania negada. São Paulo: Unesp, 1994.

JODELET, D. O movimento de retorno ao sujeito e a abordagem das representações sociais. Sociedade e Estado, Brasília, v. 24, n. 03, p. 679-712, set./dez. 2009. Disponível em: <http://www.scielo.br/pdf/se/ v24n3/04.pdf>. Acesso em: 9 maio 2011.

JOVCHELOVITCH, S. Vivendo a vida com os outros: intersubjetividade, espaço público e representações sociais. In. GUARESCHI, P.; JOVCHELOVITCH, S. (Org.). Textos em representações sociais. 12. ed. Petrópolis: Vozes, 2011.

. Os contextos do saber: representações, comunidade e cultura. Petrópolis: Vozes, 2008.

LAGE, N. Estrutura da notícia. 2. ed. São Paulo: Ática, 1987.

MAFFESOLI, M. O ritmo da vida: variações sobre o imaginário pós-moderno. Rio de Janeiro: Record, 2007.

MEDINA, C. A arte de tecer o presente: narrativa e cotidiano. São Paulo: Summus, 2003.

. Entrevista: o diálogo possível. São Paulo: Ática, 1986. 
MINAYO, M. C. S. O desafio do conhecimento: pesquisa qualitativa em saúde. São Paulo: Hucitec, 1999.

Saúde-doença: uma concepção popular da Etiologia. Cadernos de saúde Pública, Rio de Janeiro, v. 4, n. 4, p. 363-81, out./dez. 1988.

MOSCOVICI, S. Prefácio. In: GUARESCHI, P.; JOVCHELOVITCH, S. (Org.). Textos em Representações Sociais. 12. ed. Petrópolis: Vozes, 2011. p.7-15.

RÊSES, E. S. Do conhecimento sociológico à teoria das representações sociais. Sociedade e Cultura, Goiânia, v. 6, n. 2, p. 189-99, jul./dez. 2003. Disponível em: <https://www.revistas.ufg.br/fchf/article/ view/920/1123>. Acesso em: 9 maio 2011.

SANTOS, B. S. Um discurso sobre as ciências. 4. ed. São Paulo: Cortez, 2006.

SARRIERA, J. C; MOREIRA, M.C; ROCHA, K. B; BONATO, T. N; DUSO, R.; PRIKLADNICKI, S. Paradigmas em Psicologia: compreensões da saúde e dos estudos epidemiológicos. Psicologia \& Sociedade, v. 15, n. 2, p. 88-100, jul./dez. 2003.

SCLIAR, M. História do conceito de saúde. Physis: Revista de Saúde Coletiva. Rio de Janeiro, v. 17, n. 1, p. 29-41, 2007.

SÊGA, R. A. O conceito de representação social nas obras de Denise Jodelet e Serge Moscovici. Anos 90, Porto Alegre, v. 8, n. 13, jul. 2000.

SEGRE, M.; FERRAZ, F. C. O conceito de saúde. Revista de Saúde Pública, São Paulo v. 31, n. 5, p. 538-42, 1997.

TRAVERSO-YÉPEZ, Martha. A interface psicologia social e saúde: perspectivas e desafios. Psicologia em Estudo, Maringá, v. 6, n. 2, p. 49-56, jul./dez. 2001.

TURATO, E. R. Tratado da metodologia da pesquisa clínico-qualitativa: construção teórico-epistemológica, discussão comparada e aplicação nas áreas da saúde e humanas. Petrópolis: Vozes, 2003.

\section{Sobre os autores:}

Jacir Alfonso Zanatta: Doutor e mestre em Psicologia pela Universidade Católica Dom Bosco (UCDB). Mestre em Educação pela Universidade Federal de Mato Grosso do Sul (UFMS). Graduação em Psicologia - Formação de Psicólogo - pela UCDB, em Comunicação Social Habilitação em Jornalismo - pela UFMS, e em Filosofia pela Faculdades Unidas Católicas de Mato Grosso (FUCMT). É vice-presidente do Comitê de Ética na Pesquisa (CEP) e leciona nos cursos de Jornalismo, Publicidade e Propaganda, Serviço Social e Filosofia da UCDB. Psicólogo Clínico.

E-mail: jacirzanatta@gmail.com

Bianka Macário: Acadêmica do Curso de Jornalismo da Universidade Católica Dom Bosco (UCDB). Bolsista Pibic. E-mail: biankamacario@gmail.com

Silvia Santana Zanatta: Doutoranda do Programa de Pós-Graduação em Desenvolvimento Local pela Universidade Católica Dom Bosco (UCDB), bolsista Capes. Mestre em Desenvolvimento Local pela UCDB, na linha de pesquisa Desenvolvimento Local em contexto de territorialidades. Especialização em Comunicação: Linguagem, Construção Textual e Literatura pelo Instituto Catarinense de Pós-Graduação e Libera Limes Instituto de Qualificação Profissional. Graduação em Jornalismo pela Universidade para o Desenvolvimento do Estado e da Região do Pantanal (UNIDERP). Atualmente trabalha com pesquisas na região da Bacia do Rio da Prata ligadas a monitoramento de agências financiadoras do desenvolvimento, conservação ambiental, gestão territorial e comunidades tradicionais. E-mail: silviasantana1@gmail.com 
